\title{
DIFERENCIAS
}

\section{MORFOSINTÁCTICAS ENTRE}

EL ESPAÑOL DE ESPAÑA

Y EL ESPAÑOL LATINO

EN UN CAPÍTULO DE LA SERIE

FRIENDS (1999)

\author{
Antonio María López González \\ Universidad de Łódź \\ http://dx.doi.org/10.18778/8220-201-4.15
}

\section{Resumen}

En el doblaje en español se contraponen dos versiones básicas: español de España para el territorio español y español latino para Latinoamérica. El presente artículo, después de presentar brevemente ambos modelos de traducción, compara las características morfosintácticas más destacadas de ambos doblajes a partir de la transcripción de un capítulo de la serie de televisión Friends. El análisis, de tipo cuantitativo y cualitativo, presta especial atención a cuestiones pronominales, verbales y adverbiales.

Palabras claves: Doblaje, español de España, Español de América, español latino, morfosintaxis.

\section{1.}

\section{El doblaje en español en el mundo hispanohablante}

De entre las diferentes formas de traducción audiovisual (doblaje, subtitulación, voces superpuestas...), es el doblaje la modalidad 
predominante en el mundo hispanohablante, sobre todo en las series de televisión y en el cine, con gran protagonismo de los estudios de doblaje de España y México.

En el ámbito del doblaje al español, según Bravo García (2008: 6), se contraponen dos tipos lingüísticos de traducción, con designaciones que hacen referencia a marcas geográficas:

a) "Un español más tradicional y conservador hablado en España, llamado español castellano, español de España [...]”, basado en la norma de Castilla.

b) "Otro unificado, que es el que se utiliza en la América hispanohablante", con "centro de gravedad en este continente", "generalmente llamado español latino o español hispano", privado de regionalismos léxicos o gramaticales y con acentuación neutra.

La industria del doblaje en España tiene una larga tradición -desde comienzos de la dictadura de Franco-, realizándose de manera sistemática para todo lo que se emite (Bravo García, 2008: 67). Madrid y Barcelona concentran la mayor parte de esta industria.

El doblaje de España emplea la norma lingüística considerada tradicionalmente más prestigiosa, la del español centropeninsular, usada y difundida en la educación, la administración y los medios de comunicación. Ha sido, además, el modelo históricamente promovido por la RAE, correspondiéndose con los usos de ciudades como Madrid o Burgos. En este modelo la gramática del español sigue el modelo estándar, el léxico es muy rico y abunda en perífrasis verbales y construcciones fraseológicas. En cuanto a la pronunciación, hay diecinueve fonemas, así que no aparecen fenómenos como el seseo y el ceceo.

Por lo que se refiere al doblaje en América Latina, la productora Walt Disney tuvo un claro protagonismo en el desarrollo de un único doblaje en español neutro (actualmente llamado latino). Tras una primera etapa -años cuarenta- en Argentina, Disney trasladó los estudios de doblaje a México D.F., donde inició en 1950 los doblajes al llamado español neutro, utilizando un acento estándar, que era, en realidad, un español mexicano culto. A la productora Disney, le siguieron otras productoras de dibujos 
animados como Hanna \& Barbera, que desde 1960 doblaron sus series en español neutro en estudios de México y Puerto Rico, en una sola versión para todo el mercado hispanohablante, en un español inteligible para cualquier hispanohablante, libre de localismos y lo más neutro posible. Posteriormente, con el auge de la televisión en Hispanoamérica, este modelo de doblaje se consolidó para la traducción audiovisual de series extranjeras (Bravo García, 2008: 67). De este modo se creó una potente y duradera industria de doblaje al español, principalmente en territorio mexicano, aunque más tarde también presente en otros países latinoamericanos.

El español neutro o latino de los doblajes se relaciona con el español internacional (Ávila, 2011:21-28). Según Ávila (2017: 36), desde el punto de vista léxico, el español internacional, "está formado por las voces patrimoniales -las que todos usamos-, como mesa, azul, comer, así, en, $y$; más los vocablos que tienen mayor número de hablantes (frecuencia) y que se usan en un mayor número de países (dispersión)". En el plano morfosintáctico el español neutro también usa las variantes más extendidas en el español de América: uso de tú y ustedes, tendencia al uso de las formas verbales simples, ausencia de leísmo, etc. (López González, 2018: 139). En la pronunciación, según Ávila (2011: 21), “el español neutro se caracteriza por ser seseante y yeísta, es decir, porque no hace la distinción entre los fonemas /s/ y $/ \theta /$, y porque no incluye el fonema lateral líquido palatal $/ \lambda$. Además, la pronunciación de /y/ es suave, no asibilada como se escucha en el Río de la Plata". Esta pronunciación se corresponde con una de las tres normas del español internacional, la norma a, de Ciudad de México y Bogotá, caracterizadas por el seseo, la conservación de /-s/ y la articulación fricativa $[\mathrm{x}]$ en el primer caso y la articulación abierta $[\chi]$ en el segundo. 


\section{Metodología}

En este artículo, por limitaciones de espacio, nos concentraremos en el plano morfosintáctico. Por tanto, a continuación analizamos las principales diferencias morfosintácticas entre el doblaje en español de España y el doblaje en español latino, tomando como punto de referencia los trabajos de Llorente Pinto (2006: 2-5) y Bravo García (2008:43-46). El análisis será de tipo cuantitativo (valores absolutos) y cualitativo (análisis y comparación de ejemplos en contexto).

El corpus analizado es la transcripción de las dos versiones del doblaje en español (de España y latino) de un capítulo de la popular serie de televisión Friends (Amigos), producida por la NBC americana entre septiembre de 1994 y mayo de 2004, serie ambientada en Nueva York. El capítulo analizado es el no 14 de la 5. ${ }^{a}$ temporada, grabado en 1999, un episodio de enredo en el que todos los personajes se dedican a engañar a los demás.

La versión en español de España (VE) fue realizada por la empresa Sonoblock (Barcelona). Todos los actores de doblaje procedían de Barcelona. El capítulo se titula "En el que todos se enteran" (Español de España).

La versión en español latino (VL) fue grabada por la empresa de doblaje Art Sound México (Ciudad de México). Todos los actores de doblaje eran mexicanos, de Ciudad de México, excepto Yolanda Vidal, que era de Monterrey. El título del capítulo es "Cuando todos se enteran" (español latino).

\section{3.}

\section{Las formas de tratamiento}

\section{1.}

\section{El tuteo}

Tanto en la versión de España como en la de español latino, el tuteo es la forma de tratamiento normal cuando los amigos (de la serie) hablan entre sí. El tuteo se da tanto en formas verbales 
de indicativo y subjuntivo, simples o compuestas, como en el uso del verbo en modo imperativo. En ambas versiones se usa el pronombre tú y las formas átonas te, ti.

\section{ESPAÑOL DE ESPAÑA}

Tú no tienes secretos.

¿Sabes que a veces estás buscando algo

y ni siquiera eres capaz de ver que está justo delante de ti, tomando café?

Eh, Mon, ¿qué haces, te vienes al cine con nosotras?

\section{ESPAÑOL LATINO}

Vaya, no tienes ningún secreto.

¿Sabes?, a veces tú buscas algo y ni siquiera ves que está ahí frente a ti tomando café.

Oye, Mónica, ¿qué vas a hacer hoy? ¿Ves una película con nosotras?

Algunas veces no se da la correspondencia en el tuteo entre ambos doblajes. Sobre todo en los casos en que en la versión española la forma verbal de tuteo funciona como un marcador coloquial. Entonces en la versión latina aparece un marcador discursivo diferente. Otra opción es cambiar la direccionalidad del discurso de tú a ustedes (amigos).

\section{ESPAÑOL DE ESPAÑA}

Ya sabes... tu coges una lata y nosotros otra y las conectamos por un hilo...

Verás, mi abuelo era sueco y mi abuela era una diminuta conejita.

Eh, oye, si él se va, yo podría intentar quedarme con su piso. (Valor ambiguo)

No... Déjate de rollos, esto tiene que acabarse ahora.

\section{ESPAÑOL LATINO}

O sea, que tienes una lata, nosotros otra y se conectan por medio de una cuerda...

Bueno, mi abuelo era sueco y mi abuelita en realidad era una linda liebre.

Oigan, si se está mudando, debería tratar de rentar su departamento. (Dirigido al grupo)

No, ya nada, ya debe terminar, por favor. (Sin dirección explícita) 


\section{2.}

\section{Vosotros y ustedes}

Una de las diferencias morfosintácticas más características del español de América es el uso del pronombre ustedes en lugar de vosotros. En España se reserva ustedes para el tratamiento de respeto, mientras el pronombre vosotros se usa para el tratamiento de confianza. En América el uso de ustedes tiene doble fin, sirve para mostrar respeto y para mostrar confianza. En consecuencia, de manera sistemática, cuando en español latino aparece la forma de ustedes, en español de España se utiliza la forma correspondiente a vosotros.

\section{ESPAÑOL DE ESPAÑA}

Sí, pero sabéis qué, no importa quién sabe qué.

Eh, fijaos, fijaos. El tío feo desnudo tiene un amigo desnudo.

Creía que os lo estabais montando, no sabía que estuvierais enamorados.

\section{ESPAÑOL LATINO}

Sí, pero saben qué, ya no importa quién lo sabe.

Oigan, oigan. Vean esto, vean esto. El señor desnudo tiene un amigo desnudo.

Yo creí que eso no lo hacían. No sabía que se amaban.

Esta diferencia afecta también al uso de los pronombres personales, pues a las formas españolas vosotros, os, vuestros, etc. les corresponden las formas americanas ustedes, les, sus, etc. Se observa que, en el segundo ejemplo, aparece el pronombre átono les que focaliza sobre ustedes (los amigos), mientras que en la versión española la pregunta es impersonal. En cuanto al tercer ejemplo, a "vuestros secretos" -España- le corresponde "sus secretos" (de ustedes) -Latino-, y a "sus secretos" (de ellos) -España- "los de ellos", en un uso elíptico del posesivo analítico pospuesto frecuente en América (Vaquero de Ramírez, 2003: 17).

\section{ESPAÑOL DE ESPAÑA}

Sería estupendo vivir enfrente de vosotros.

\begin{tabular}{ll}
\hline Eh, ¿qué pasa aquí? & Eh, ¿qué les sucede? \\
\hline Conozco vuestros secretos, conozco sus & Tengo sus secretos, y tengo los de ellos \\
secretos y conozco mis propios secretos. & y tengo mis secretos, ¿o no? \\
\hline
\end{tabular}

\section{ESPAÑOL LATINO}

Y sería genial vivir enfrente de ustedes. 


\section{4.}

\section{Uso de los pronombres le/s, lo/s, la/s}

En la versión española aparece leísmo para el Complemento Directo de persona, mientras que la versión americana utiliza las formas lo, la, los, las a las que corresponde etimológicamente ejercer esa función.

"El leísmo es raro" en América, aunque hay casos "no enteramente esporádicos ni asistemáticos" (Moreno de Alba, 2007: 164). Además, los fenómenos de loísmo y laísmo son desconocidos allí. La consecuencia de lo anterior es que en el español latino no se dan leísmo, loísmo ni laísmo.

\section{ESPAÑOL DE ESPAÑA}

Estábamos en el piso del tío feo desnudo y les vimos montándoselo por la ventana. De hecho, les vimos montándoselo contra la ventana.

Es una gran idea y conozco al tío feo desnudo porque llevamos casi cinco años observándole lo cual me devuelve mi ventaja.

\section{ESPAÑOL LATINO}

Estábamos en el departamento del hombre desnudo y los vimos haciéndolo junto a la ventana. No es cierto, los vimos haciéndolo contra la ventana.

Esa es una gran idea y conozco al señor desnudo porque lo observamos por unos cinco años y eso me devuelve mi deseo.

De otra parte, al igual que constatara Llorente Pinto (2006: 3), en la versión latina se documenta la ausencia del pronombre de $\mathrm{CD}$ con algunos verbos como saber:

\section{ESPAÑOL DE ESPAÑA}

O podríamos no decirles que lo sabemos $y$ divertirnos a su costa.

Phoebe lo sabe y por eso intenta hacernos alucinar.

\section{ESPAÑOL LATINO}

O mejor no decimos que sabemos y nos divertimos mucho.

Phoebe sabe y solo quiere asustarnos.

Diferencias morfosintácticas... 


\section{5.}

\section{Usos verbales}

\section{1 .}

\section{La oposición canté / he cantado}

Como indica Moreno de Alba (2007: 182), "en el español peninsular, para el uso de canté o he cantado, es relevante el que la acción tenga o no relación con el presente". Si la acción pasada no tiene relación con el presente, se usa el pretérito perfecto simple (pretérito); en cambio, si la acción se produce en un periodo desde un punto del pasado hasta el momento presente del que se habla -hoy, ahora, estos días-, se usa el pretérito perfecto compuesto (antepresente). Como se ve en los ejemplos, a los pretéritos simples españoles les corresponde el mismo tiempo verbal en la versión latina, a no ser que cambie la clase semántica del verbo: la gente se volvió loca... (resultado, efecto) frente a muchos se morían por... (estado).

\section{ESPAÑOL DE ESPAÑA}

\section{ESPAÑOL LATINO}

Jamás creí que llegaría a decir esto...

Oye, nunca pensé que diría esto...

De hecho, les vimos montándoselo contra

No es cierto, los vimos haciéndolo contra

la ventana. la ventana.

Pues sí, una vez nos enviaron una cesta al trabajo y la gente se volvió loca con esas mini magdalenas. Fue un día estupendo.
Bueno, sí, enviaron una vez un paquete al trabajo y muchos se morían por esos ricos muffins. Y fue un día bello.

En el español americano, en los pasados rige el valor aspectual perfectivo, de acción acabada, con preferencia por el pretérito perfecto simple (pretérito) frente al pretérito perfecto compuesto (antepresente). Si la acción expresada por el verbo ya ha llegado a su fin, se emplea el pretérito perfecto simple, independientemente de que ocurra dentro del presente ampliado. 
Hoy me ha pasado algo extraño en el café. Creo que Phoebe me ha tirado los tejos.

No creo que se rinda, ha ido a por la crema.

Vale, dame un minuto. ¿Has hecho limpieza?
Bueno, algo raro pasó en la cafetería. Creo que Phoebe estaba ligándome.

Rachel, no se va a retractar, fue a traer loción.

Ahora, dame un segundo. Oye, ¿tú

limpiaste aquí?

En cuanto al uso del pretérito perfecto compuesto (he cantado), según Lope Blanch (1972: 131 apud Moreno de Alba, 2007: 180), "la forma compuesta en México expresa acciones durativas o imperfectas; fenómenos que, aunque iniciados en el pasado, se continúan en el momento presente". Este carácter imperfectivo se aprecia en los dos únicos casos de pretérito perfecto compuesto en la versión latina.

\section{ESPAÑOL DE ESPAÑA}

Tíos, ya he visto alrededor de mil pisos este mes...

Soy una de las personas que ha solicitado su piso y me doy cuenta de que la competencia es bestial...

\section{ESPAÑOL LATINO}

Oigan, ya he ido a ver como trescientos departamentos este mes... ...soy una de las personas que solicitó su departamento y ya he notado que la competencia es mucha...

Debido al empleo peculiar de los pretéritos en América, la proporción del número de formas verbales entre ambos tiempos es muy distinta de una versión a otra. Así, es muy equilibrada en la versión española, mientras que en la versión latina se da un uso casi exclusivo del pretérito perfecto simple.

\begin{tabular}{lc|c} 
& ESPAÑOL DE ESPAÑA & ESPAÑOL LATINO \\
\cline { 1 - 3 } Pretérito Indefinido & 14 & 37 \\
\hline Pretérito Perfecto & 18 & 2 \\
\hline
\end{tabular}


La preferencia por el pretérito perfecto simple en detrimento del compuesto se enmarca en una tendencia más general de bajo uso de las formas compuestas en la versión latina. Así, se documenta también la sustitución del pretérito pluscuamperfecto de subjuntivo de la versión española por el pretérito imperfecto de subjuntivo en la versión latina.

\section{ESPAÑOL DE ESPAÑA}

Madre de Dios, este piso me encanta. Verdad que es perfecto. Es increíble que no me hubiera dado cuenta de lo genial que era.

\section{ESPAÑOL LATINO}

Oh por dios, iqué hermoso departamento! ¿No está perfecto? Es increíble que jamás notara lo lindo que es.

\section{2.}

\section{Futuro sintético vs. Futuro analítico}

En consonancia con el poco uso del futuro de indicativo en el español de América (Moreno de Alba, 2007: 176-178), en la versión de español latino el futuro sintético en -re es menos usado que en la versión de España. Las proporciones de uso de la perífrasis $<$ ir $a+$ infinitivo $>$ se invierten, siendo mucho más frecuente en la versión latina que en la versión de español de España, como se muestra en la siguiente tabla:

\section{ESPAÑOL DE ESPAÑA}

\begin{tabular}{lcc}
\hline Futuro $-r e ́$ & 25 & 13 \\
\hline $\begin{array}{l}\text { Perífrasis } i r a+ \\
\text { infinitivo }\end{array}$ & 12 & 25 \\
\hline
\end{tabular}

La forma perifrástica sustituye al futuro simple en la versión latina para hablar sobre planes, intención, acciones futuras, etc. 
Oooh, echaré de menos ese culo flácido.

Oooh, voy a extrañar a su feo trasero burdo.

Bueno, tengo que recoger, a ver... pero ya $A h$, tengo que ir a recoger a Ben. Pero voy se me ocurrirá algo. a pensar algo bueno.

Tranquilo, se rendirá mucho antes que tú. Tranquilo, se va a retractar mucho antes que tú.

Además, hay que notar que en la versión latina la perífrasis verbal <ir $a+$ infinitivo $>$ se conjuga, no solo en presente, sino también en pretérito imperfecto o en futuro, sustituyendo así también a otras formas verbales en presente y a otras perífrasis de la versión española:

\section{ESPAÑOL DE ESPAÑA}

...estaban... ya sabes, lavando ropa o haciendo la compra...

Ehm, la verdad es que pensaba hacer la colada.

\section{ESPAÑOL LATINO}

...iban a no sé... a la lavandería o iban a hacer las compras...

Ehm, es que yo iba a ir a la lavandería.

Voy a por la crema.

Iré a traer loción.

\section{3.}

\section{Las perífrasis verbales}

Autores como Bravo García (2008: 45), García Aguiar (2011: 133) o Mendoza Sander (2015: 103) han documentado un uso diferente de las perífrasis verbales en los doblajes en español de España y español latino. En el corpus analizado hay claras diferencias cuantitativas y cualitativas en el uso de las perífrasis.

Así, se observa una mayor cantidad y variedad de perífrasis verbales en la versión española (VE: 85) que en la versión latina (VL: 70). La única categoría de perífrasis en la que la versión latina supera a la española es en la de <ir $a+$ infinitivo $>$ (VE: 12; VL: 25), que se corresponde mayormente con formas de futuro simple en 
la versión española. Si se descuentan estas perífrasis del cómputo general, la diferencia es aún más marcada (VE: 73; VL: 45).

Ambas versiones comparten un alto número de casos de la perífrasis progresiva <estar + gerundio $>$ (VE: 14; VL: 11). En el caso de la perífrasis modal $<$ poder + infinitivo $>$ la versión española casi duplica el número de perífrasis de este tipo de la versión latina (VE: 23; VL: 14). Aunque con frecuencias mucho menores, en las perífrasis de obligación se da cierta preferencia por el uso de $<$ deber + infinitivo $>$ en la versión latina, preferencia que se torna a favor de $<$ tener que + infinitivo $>$ en la versión española. Los dos únicos casos de la forma <hay que + infinitivo $>$ se dan en la versión latina.

\section{PERÍFRASIS VERBALES}

ESPAÑOL DE ESPAÑA

ESPAÑOL LATINO

\begin{tabular}{lcl} 
deber + infinitivo & 3 & 6 \\
\hline dejar de + infinitivo & 3 & 2 \\
\hline estar + gerundio & 14 & 11 \\
\hline estar + participio & 1 & 2 \\
\hline haber que + infinitivo & - & 2 \\
\hline intentar + infinitivo & 4 & 1 \\
\hline ir $a+$ infinitivo & 12 & 25 \\
\hline llegar $a+$ infinitivo & 2 & - \\
\hline llevar + gerundio & 2 & - \\
\hline pensar + infinitivo & 2 & - \\
\hline poder + infinitivo & 23 & 14 \\
\hline seguir + gerundio & - & 1 \\
\hline tener que + infinitivo & 5 & 3 \\
\hline tratar de + infinitivo & - & 2 \\
\hline volver $a+$ infinitivo & 3 & 1 \\
\hline otras 11 perífrasis diferentes & 11 & - \\
\hline Total & 85 & 70 \\
\hline
\end{tabular}


Por lo demás, hay más variedad de perífrasis verbales en la versión española: 23 perífrasis distintas frente a 12 perífrasis diferentes en la versión latina. En la celda "otras 11 perífrasis diferentes" se recogen 11 perífrasis que aparecen solo en la versión española, cada una con una sola ocurrencia: $<a c a b a r+$ gerundio $\rangle,<a c a b a r$ de + infinitivo $>,<$ dar ganas de + infinitivo $>,<$ dejar + infinitivo $>$, $<$ dejar + participio $>,<$ empezar $a+$ infinitivo $>,<$ parar de + infinitivo $>$, $<$ pasar + gerundio $>$, $<$ ser capaz de + infinitivo $>$, $<$ soler + infinitivo $>$, <tener ganas de + infinitivo $>$. En la versión española hay también otras tres perífrasis con dos casos cada una: <llegar $a+$ infinitivo $>,<$ llevar + gerundio $>,<$ pensar + infinitivo $>$. Las perífrasis exclusivas de la versión latina son: $<$ hay que + infinitivo $>$ (2), <tratar de + infinitivo $>$ (2) y < seguir + gerundio $>$ (1).

Muchas de las perífrasis presentes en la versión española son sustituidas por tiempos simples o reformuladas con otros verbos o expresiones:

\section{ESPAÑOL DE ESPAÑA}

...mirad, el tío feo desnudo está

empaquetando sus cosas.

...todo el rato que Mónica se pasaba

hablando con la pobre Linda...

¿Sabes que a veces estás buscando algo

y ni siquiera eres capaz de ver que está

justo delante de ti, tomando café?

Phoebe acaba de enterarse de lo de

Mónica y Chandler.

No, no puedo soportar más secretos.

Jo, vaya, tengo ganas de conseguir ese piso.

¿Cómo has llegado a ser tan mono?

\section{ESPAÑOL LATINO}

...vean al hombre desnudo. Pone cosas en una caja.

...todo el tiempo que Mónica pasaba al teléfono con Linda su amiga.

¿Sabes?, a veces tú buscas algo y ni siquiera ves que está ahí frente a ti tomando café.

Phoebe se enteró sobre Mónica $y$ Chandler.

No, ya no quiero más secretos.

Vaya, deseo mucho el departamento.

¿Cómo es que eres tan tierno? 


\section{6.}

\section{Usos adverbiales americanos}

Mientras que en la versión de España se usa únicamente el adverbio aquí, en la versión latina aparece el adverbio acá, aunque alternando con aquí.

ESPAÑOL DE ESPAÑA

\begin{tabular}{lll}
\hline aquí & 8 & 5 \\
\hline acá & 0 & 4 \\
\hline
\end{tabular}

En la versión latina hay un uso diferenciado de ambos adverbios: acá aparece con un valor de movimiento siempre con el verbo venir, en tanto que aquí funciona como un complemento circunstancial estático.

\section{ESPAÑOL DE ESPAÑA}

Joey, ven aquí, ven aquí.

\section{ESPAÑOL LATINO}

Joey, ven acá, ven acá.

Sí. Oye, Joey no estará en casa esta noche, Sí, Joey no va a estar en la noche, por qué así que por qué no vienes... no vienes acá...

...hola, un momento, está aquí ...oye, aguarda un segundo, está aquí.

...yo intentaré oírlo todo desde aquí. ...yo voy a tratar de escuchar desde aquí.

¿Has hecho limpieza? Oye, ¿tú limpiaste aquí?

Además, al igual que Herrero Sendra (2014: 33) documentó, también en nuestro caso en la versión latina aparece el uso del ya desemantizado, carente de significado:

\section{ESPAÑOL DE ESPAÑA}

Será mejor que nos vayamos, si queremos ver la película.

Oye Ross, cariño, tienes que dejar de torturarte.

\section{ESPAÑOL LATINO}

Oye linda, ya vámonos. Hay que ver la película.

Oye Ross, cielo, ya deja de torturarte tú mismo. 


\section{7.}

\section{Conclusiones}

En la traducción audiovisual en español se suelen contraponer dos versiones básicas: español de España y español latino. La versión española responde a una larga tradición de doblaje con una adscripción geográfica explícita, aunque con un modelo lingüístico procedente de una de las regiones de este país: Castilla. La versión de español latino tiene un origen comercial, impulsado por las productoras cinematográficas norteamericanas desde los años 50, buscando la rentabilidad a partir del diseño de una variedad neutra, no marcada y aceptable en todos los países hispanoamericanos, tomando como base las características lingüísticas comunes o prestigiosas de las distintas variedades del español americano.

En este artículo hemos prestado atención a las diferencias morfosintácticas más notables en el doblaje entre el español de España y el español latino, comparando sendas versiones de un capítulo de la serie de televisión Friends (1999), con doblajes realizados respectivamente en España y México. El análisis se ha concentrado en cuestiones pronominales, verbales y adverbiales.

En las formas de tratamiento, a excepción de los marcadores coloquiales, se constata un uso semejante del tuteo, también en la versión de español latino, lo que no debe extrañar, ya que "ahora se usa solo el tuteo en la mayor parte del territorio americano" (Moreno de Alba, 2007: 165). Por el contrario, la diferencia es muy marcada en la segunda persona del plural. En el español de España se da un uso general del pronombre vosotros y sus formas asociadas en el paradigma pronominal y en la flexión verbal, en tanto que en el español latino, al no existir vosotros en el español americano, es sustituido sin excepción por ustedes y las formas correspondientes de tercera persona del plural en el paradigma verbal y pronominal. Igualmente el uso de los clíticos le/s, la/s, $l o / s$, determinan una diferencia clara entre ambas versiones. El leísmo de persona aparece de manera común en la versión española, mientras que el uso de los pronombres átonos de complemento directo es totalmente etimológico en la versión latina. 
Por lo que respecta a las formas verbales, se aprecia una simplificación en su uso. Así, en el caso del pretérito perfecto simple y compuesto la proporción de uso es muy similar en la versión española, en tanto que en la versión latina casi solo aparece la forma simple. De igual modo, el número de perífrasis verbales, tanto en número total de perífrasis como en número de perífrasis diferentes, es menor en la versión latina. Las perífrasis de la versión española son sustituidas por tiempos simples o reformuladas con otros verbos o expresiones. La situación se invierte con los futuros. En la versión española se usa el futuro simple, al que le corresponde en la versión latina la perífrasis $<$ ir $a+$ infinitivo $>$, en consonancia con su amplio uso en el continente americano.

En los usos adverbiales se nota un uso exclusivo de la forma aquí en la versión española, frente a la aparición de acá en la versión latina, aunque siguen apareciendo casos de aquí también en la versión latina. Finalmente, en la versión americana aparecen casos del adverbio ya desemantizado.

\section{Referencias bibliográficas}

Ávila, R. (2011), “El español neutro (?) en los medios de difusión internacional”, en R. Ávila (ed.), Variación del español en los medios, México DF: El Colegio de México, 17-30.

Ávila, R. (2015), "En el límite de las lenguas romances: las telenovelas hispánicas en Rumanía”, en N.Rentel, T.Schröder y R. Schröpf (eds.), Kommunikative Handlugsmuster im Wandel? ¿Convenciones comunicativas en proceso de transformación?, Frankfurt: Peter Lang, 233-247.

Ávila, R. (2017), "Full Metal Jacket: Versiones en español y en latino", Revista Clepsydra, 16, 35-47.

Bravo García, E. (2008), El español internacional: conceptos, contextos y aplicaciones, Madrid: Arco/Libros.

García Aguiar, L. C., y García Jiménez, R. (2011), “La influencia del sistema meta en traducción: el doblaje de Los Picapiedra al español neutro", Estudios de Traducción, Vol. 1, 127-138.

Herrero Sendra, A. (2014), El español neutro en el doblaje de Los Aristogatos: un estudio de caso, Trabajo fin de Grado, Castellón de la Plana: Universitat Jaume I. 
Llorente Pinto, M. R. (2006), "Qué es el español neutro", Cuadernos del Lazarillo: Revista literaria y cultural, 31, 2006, 77-81, [en línea] http://gredos.usal.es/jspui/bitstream/10366/121976/3/ DLE_LlorentePinto_Que_es_espanol_neutro.pdf, [fecha de consulta: 24.08.2019].

Lope Blanch, J. M. (1972), "Sobre el uso del pretérito en el español de México”, en J. M. Lópe Blanch (ed.), Estudios sobre el español de México, México: UNAM, 127-140.

López González, A. M.a (2018), "Español neutro - español latino. Caracterización y realidad”, en J. Bień, B. Brzozowska-Zburzyńska, A. M. ${ }^{a}$ López González, W. Nowikow (eds.), Lingüistica hispánica en Polonia: tendencias y direcciones de investigación, colección "Manufactura Hispánica Lodziense" 4, Łódź: Wydawnictwo Uniwersytetu Łódzkiego, 131-144.

Mendoza Sander, M. (2015), El doblaje y el español neutro en las películas de animación de Disney, Trabajo fin de Grado, Vic: Universitat de Vic - Universitat Central de Catalunya.

Moreno de Alba, J. G. (2007), Introducción al español americano, Madrid: Arco Libros.

Vaquero de Ramírez, M. (2003), El español de América II. Morfosintaxis y Léxico, 3. ed., Madrid: Arco Libros. 